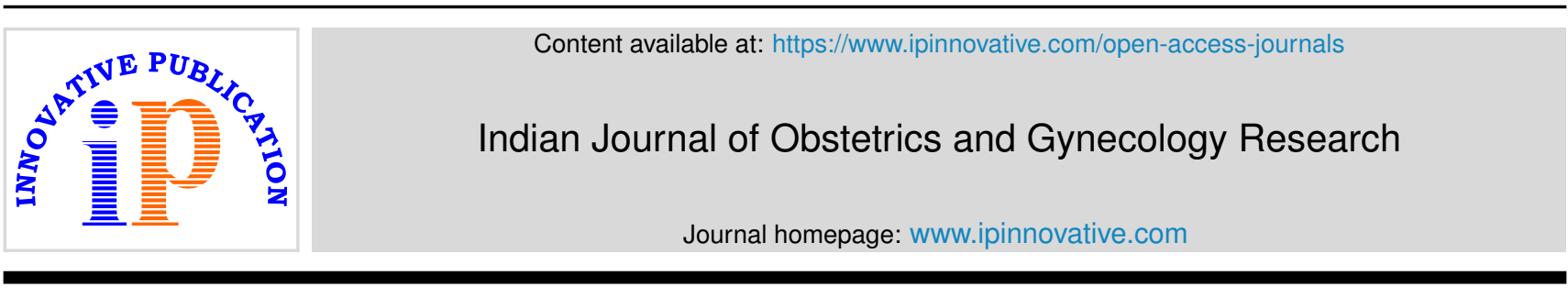

Original Research Article

\title{
Association of maternal serum ferritin concentration with newborn iron stores in anemic women in late pregnancy
}

\author{
Monica $^{1}{ }^{1}$, Sunita Maheshwari ${ }^{1}$, Archana Bamaniya ${ }^{1}$ \\ ${ }^{1}$ Dept. of Obstetrics and Gynaecology, RNT Medical College, Udaipur, Rajasthan, India
}

\section{A R T I C L E I N F O}

\section{Article history:}

Received 27-05-2020

Accepted 01-06-2020

Available online 12-09-2020

\section{Keywords:}

Serum ferritin levels

Anaemia

Iron deficiency

Pregnancy

\begin{abstract}
A B S T R A C T
Introduction: Pregnant women are particularly vulnerable to Iron deficiency because of the increased metabolic demands imposed by pregnancy involving a growing placenta, fetus and maternal tissues, coupled with associated dietary risks. Maternal iron deficiency has effects on fetal iron stores. The fetus receives iron indirectly from the maternal circulation through a rapid and unidirectional process. Thus, this study was planned to determine association between maternal serum ferritin and new born serum ferritin levels.

Materials and Methods: In this observational cross sectional study randomized sample of 100 antenatal women, $>20$ years of age with $\mathrm{Hb}<11 \mathrm{gm} / \mathrm{dl}$ and period of gestation $>37$ weeks was taken for study. Serum ferritin was estimated by ELISA technique.

Results: $\mathrm{Hb}$ levels ranged from 3.8-10.7grams/dl with a mean value of $9.77 \pm 1.55 \mathrm{gram} / \mathrm{dl}$. Parity is of significance for severity of Anaemia ( $\mathrm{p}=0.002$ ). Mean gestational age was $38.35 \pm 0.85$. No correlation was found between the maternal haemoglobin and maternal serum ferritin levels in women with mild and moderate Anaemia. But in cases of severe Anaemia a positive correlation was found with a $\mathrm{p}<0.001$. The mean cord blood serum ferritin was $57.36 \pm 19.48$ micrograms.

Conclusion: This study establishes the effect of iron deficiency anaemia on neonatal iron status with increasing severity of anaemia and emphasizes on the need for iron supplementation during pregnancy.

(C) 2020 Published by Innovative Publication. This is an open access article under the CC BY-NC license (https://creativecommons.org/licenses/by-nc/4.0/)
\end{abstract}

\section{Introduction}

Anaemia is defined as a condition when the circulating levels of haemoglobin are quantitatively or qualitatively lower than normal. ${ }^{1}$ Iron deficiency anaemia is the most common type of Anaemia in pregnant women particularly in developing countries. ${ }^{2}$

Anaemia is considered if haemoglobin level is less than $11 \mathrm{gm} \%$ and further classification by ICMR isMild anaemia - haemoglobin from 10-10.9gm\%, Moderate Anaemia - haemoglobin from 7-9.9gm\%, Severe Anaemia - less than $7 \mathrm{gm} \%$, Very severe anaemia - less than $4 \mathrm{gm} \% .{ }^{3}$ According to The Centres for Disease Control and Prevention, Anaemia is defined as haemoglobin concentration of less than $11 \mathrm{~g} / \mathrm{dl}$ in the first and third

\footnotetext{
* Corresponding author.

E-mail address: drmonicasinghmt2016@gmail.com (Monica).
}

trimesters, and less than $10.5 \mathrm{~g} / \mathrm{dl}$ in the second trimester in pregnant women. ${ }^{2}$ The World Health Organization cut-off point for diagnosis of Anaemia in pregnancy is haemoglobin less than $11 \mathrm{gram} / \mathrm{dl} .^{4}$

There is disproportionate increased plasma volume and red cell mass during pregnancy resulting in physiological Anaemia of pregnancy. The increase in red cell mass during pregnancy is consequent to augmented erythropoiesis which is associated with increased demand of erythropoeitic factors, iron being the most important. This results in increased demand of iron which is mobilized from the stores which are mainly in the form of ferritin in our body. ${ }^{5}$

Pregnant women are particularly vulnerable to Iron deficiency because of the increased metabolic demands imposed by pregnancy involving a growing placenta, fetus and maternal tissues, coupled with associated dietary risks. In developing countries pregnant women commonly begin 
gestation with depleted or low body iron stores which might make them prone to developing iron deficiency anaemia. The responsible constellation of factors producing IDA generally precedes the pregnancy, including diet poor in iron content coupled with menstrual losses and a rapid succession of pregnancies. Thus, the severity of the anaemia is inversely related to the amount of iron reserve. ${ }^{6}$

Maternal iron deficiency has effects on fetal iron stores. The fetus receives iron indirectly from the maternal circulation through a rapid and unidirectional process. Maternal iron is transported to the placenta, bound to a protein: maternal transferrin, ${ }^{7}$ which does not cross the placenta. Iron then binds to a protein with the same structure, fetal transferrin, and is transported through the blood stream to fetal tissues. ${ }^{8}$

Serum ferritin is a more sensitive indicator of iron stores than haemoglobin and provides a better indication of iron status.

Iron deficiency anaemia is regarded as the most important preventable cause of perinatal complications such as premature delivery, intrauterine growth restriction and neonatal and perinatal deaths. It is vital for early brain growth and function because it supports neuronal and glial energy metabolism, neurotransmitter synthesis and mylenation. It also adversely influence cognitive, emotional, motor and neuropsychological development. ${ }^{9}$

Transfer of iron from the mother to the fetus is supported by a substantial increase in maternal iron absorption during pregnancy. The transfer of iron from mother to fetus is regulated by placenta. A pregnant woman requires around $1000 \mathrm{mg} / \mathrm{d}$ of iron to meet the needs of pregnancy. The fetus accumulates iron at the rate of $1.35 \mathrm{mg} / \mathrm{kg} / \mathrm{day}$ of fetal weight in third trimester, when fetal brain is undergoing rapid development. ${ }^{10}$

The placental iron transfer system regulates iron transport to the fetus. When maternal iron status is poor, the number of placental transferrin receptors increases so that more iron is taken up by the placenta. Ultimately, however, the entire maternal unit becomes iron deficient and upregulation of the placental transfer cannot result in enough iron transfer to restore fetal iron pools to normative levels. The fetus will then start showing decreased serum ferritin and ultimately decreased haemoglobin or signs of iron deficiency at birth. ${ }^{11}$

All term infants are assumed to have sufficient iron during the first three months since most of the total body iron is contained within the circulating haemoglobin. After three months of age, iron stores are usually mobilized to meet the erythropoetic demands of expanding total haemoglobin mass because breast milk is not sufficient to meet the demands of growth. As a result, the level of plasma ferritin declines. Infants with small iron stores will deplete iron earlier than those with ample iron stores. Therefore anaemia during perinatal period may be a risk factor for development of iron deficiency anaemia in infancy. ${ }^{12}$

Iron is essential for neurotransmission, energy metabolism, and myelination in the developing brain. In humans, the brain growth spurt begins in the last trimester of pregnancy and extends through the first 2 years of life. Numerous studies showed lower cognitive and motor test scores in infants with iron deficiency anaemia (IDA) that persist being low even though they received iron treatment as infants. There is direct evidence of biochemical abnormalities in brains of iron-deficient infants, which demonstrated a slowed nerve conduction velocity in iron-deficient infants at 6 months of age. ${ }^{13}$

The competing demands of mother and fetus may disturb the normal maternal-fetal iron homeostasis. This may have a resultant effect both on the mother and on the fetus, such as premature delivery, intrauterine growth retardation, and neonatal and perinatal death. ${ }^{14}$

So understanding the relationship between maternal and fetal iron status may help in further efforts to prevent iron deficiency in pregnancy and infancy and improve outcomes for mother and infants. Thus, this study was planned to find out the effect of iron deficiency anaemia on new born iron stores.

\section{Aim and Objective}

To determine association between maternal serum ferritin and new born serum ferritin levels.

\section{Materials and Methods}

Approval was taken from the Institutional Ethical Committee of R.N.T. Medical College, Udaipur. Written and informed consent was taken from all patients. The study was conducted in the department of Obstetrics and Gynaecology, R.N.T. Medical College, Udaipur.

\subsection{Period of study}

January2018 to June 2018.

\subsection{Study design}

Observational Cross Sectional Study.

\subsection{Sample size}

A randomized sample of 100 antenatal women, $>20$ years of age with $\mathrm{Hb}<11 \mathrm{gm} / \mathrm{dl}$ and period of gestation $>37$ weeks was taken for study.

\subsection{Inclusion criteria}

1. Antenatal women of $>20$ yrs of age.

2. With Period of Gestation $>37$ weeks.

3. Haemoglobin $<11 \mathrm{gm} / \mathrm{dl}$ and red cell indices suggestive of iron deficiency Anaemia. 


\subsection{Exclusion criteria}

1. Maternal chronic illness like diabetes, hypertension.

2. Any history of antepartum haemorrhage.

3. High risk pregnancy like history of recurrent abortion, trauma, severe infection, severe hyperemesis, preeclampsia.

4. Multiple pregnancies.

5. Previous history of haemoglobinopathies.

\subsection{Methodology}

Antenatal women fulfilling the inclusion criteria who were admitted in the department of Obstetrics and Gynaecology R.N.T. Medical College were evaluated for-detailed history was taken and clinical examination of the patients was done. Baseline maternal data with regard to age, parity, socio-economic status and previous obstetric history with regard to birth weight and gestation was recorded in all cases. Details of clinical examination was recorded including obstetric findings, pelvic assessment was done. Ultrasonographic examination was done to assess fetal well being. Standard hospital protocols were followed in the management of labour in all the patients. Strict aseptic precautions were observed during vaginal examination and conduct of delivery. Maternal blood sample for serum ferritin estimation was taken during intrapartum period. After delivery of the neonate and cord clamping, cord blood samples were taken from placental side of the cord for foetal haemoglobin and ferritin estimation. The mothers were carefully monitored for any complication. Patients and their neonates were followed till discharge.

\subsection{Blood sampling}

MOTHERS: $5 \mathrm{ml}$ of venous blood was taken and about $2 \mathrm{ml}$ from these samples was taken in EDTA vacutainers for haemoglobin measurement and rest was left to clot at room temperature. After centrifugation serum was separated and stored at $-20^{\circ} \mathrm{C}$ from which serum ferritin levels were determined.

NEW BORNS: $5 \mathrm{ml}$ of cord blood was taken immediately after cord clamping from placental side of cord. About $2 \mathrm{ml}$ from these samples was taken in EDTA vacutainers for haemoglobin measurement. Rest was left to clot at room temperature and similar procedure was done for serum ferritin estimation.

1. Haemoglobin was estimated by coulter method using SYSMEX K X 21 (automated hematology analyzer).

2. Serum ferritin was estimated by ELISA technique (it uses solid phase direct sandwich Elisa) as per manufacturer's instruction:

\subsection{Estimation of serum ferritin}

\subsubsection{Principle}

Serum ferritin estimation is based on principle of Enzyme Linked Immunosorbant Assay. Reagents used in the immunoenzymatic assay include high affinity and specificity antibodies (enzyme and immobilized), with different and distinct epitope recognition, in excess, and native antigen. In this procedure, immobilization takes place during the assay at surface of a microplate well through the interaction of streptavidin coated on the wall and exogenously added biotinylated monoclonal mouse IgG anti- ferritin antibody.

Upon mixing monoclonal biotinylated antibody, and a serum containing Ferritin reaction results between Ferritin and the antibody, forming an antibody-antigen complex. Simultaneously the biotin attached to the antibody binds to the streptavidin coated on the microwells resulting in immobilization of the complex.

After a suitable incubation period, the antigen-antibody bound fraction is separated from unbound antigen by decantation or aspiration.

Another antibody (directed at a different epitope) labeled with an enzyme, Enzyme labeled anti ferritin IgG antibody is added. Another interaction occurs to form an Enzyme labeled antibody- antigen -biotinylated antibody complex on the surface of wells. A suitable substrate is added to produce color measurable with the use of a microplate spectrophotometer. The enzyme activity on the well is directly proportional to the free antigen concentration.

\subsubsection{Specimen collection, processing and storage}

Collected blood was allowed to clot which was centrifuged to separate the serum from the cells. Serum samples were stored at $-20^{\circ} \mathrm{C}$ for further repeat testing in case required.

\subsubsection{Instruments and materials used}

1. Distilled water or deionized water.

2. Precision pipettes.

3. Disposable pipette tips.

4. Microplate reader with $450 \mathrm{~nm}$ and $620 \mathrm{~nm}$ wavelength absorbance capability.

5. Absorbent paper for blotting the microplate wells.

6. Graph paper.

\subsubsection{Reagents provided}

1. Ferritin caliberators-1 $\mathrm{ml}$ per vial A-F.

2. Biotinylated (MoAb) antibody-13 $\mathrm{ml}$ per vial.

3. Enzyme labelled Anti-Ferritin IgG-13 ml per vial.

4. Streptavidin Coated Microplate-96 wells.

5. Wash Solution concentrate- $20 \mathrm{ml}$.

6. TMB-Subtrate- $13 \mathrm{ml}$ per vial.

7. Stop solution $-8 \mathrm{ml}$ per vial. 


\subsubsection{Reagent preparation}

Wash buffer preparation-content of wash solution concentrate was diluted as mentioned on the bottle labels with distilled water in a suitable storage container. This solution can be stored at room temperature up to 60 days.

\subsubsection{Test procedure}

1. Before proceeding with the assay all reagents, serum, references and controls were brought at room temperature $\left(20-27^{\circ} \mathrm{C}\right.$. $)$.

2. Microplate wells were formatted for each serum, reference, controls and patient specimen to be assayed.

3. 25 micro litres of the appropriate serum reference control or specimen was pipetted into the assigned well.

4. 100 micro litres of the biotinylated antibody was added to each well.

5. Microplate gently swirled for 20-30 seconds to mix and then covered

6. Incubated for 30 minute at room temperature, then the contents of the microplate were discarded.

7. 300 Microlitres of wash buffer was added \& aspirated Repeated two additional times for a total of three washes.

8. 100 micro litres of the anti ferritin-enzyme labelled antibody was added to each well.

9. Microplate was gently swirled for 20-30 seconds to mix, then covered and Incubated for 30 minutes at room temperature.

10. The contents of the microplate were discarded by decantation or aspiration.

11. 300 micro litres of wash buffer was added and then decanted or aspirate. Repeated two additional times for a total of three washes.

12. 100 micro litres of TMB substrate solution was added in each well.

13. 50 micro litres of stop solution was added to each well and mix gently for 15-20 seconds.

14. The absorbance in each well was read at $450 \mathrm{~nm}$ (using a reference wavelength of $620-630 \mathrm{~nm}$ to minimize well imperfections) in a microplate reader. The results should be read within thirty minutes of adding the stop solution.

\subsubsection{Calculation of results}

1. The average absorbance value (optical density) was calculated for each of the standards and sample with the help of the ELISA reader.

2. A standard curve was created by plotting the optical density for each standard concentration the ordinance against Serum Ferritin concentration on the abscissa. A best fit curve was drawn through the points of the graph. Figure 1ig.1- Standard curve for serum ferritin
ELLSA.

3. To determine the concentration of the serum ferritin for each sample, first the mean absorbance value was found on the ordinate and then a horizontal line was extended to the standard curve, at the point of intersection, a vertical line was extended to the abscissa and the corresponding serum ferritin concentration was read.

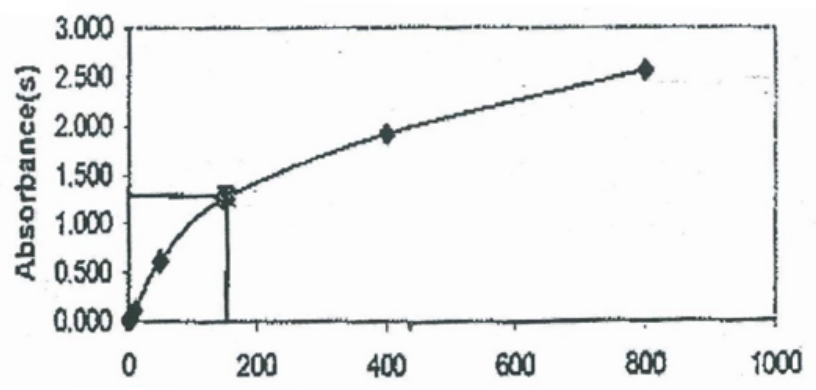

Ferrtin values in ug/L

Fig. 1: Representative standard curve for serum ferritin ELISA

Sensitivity: Ferritin microplate ELISA procedure gives a sensitivity of 1 nano gram $/ \mathrm{ml}$.

\subsection{Outcome variables}

1. Maternal serum ferritin level.

2. New born haemoglobin and serum ferritin levels.

\section{Observations and Results}

Blood sampling for serum ferritin estimation was done. After delivery $5 \mathrm{ml}$ of cord blood was drawn from placental side and estimation of cold blood haemoglobin and serum ferritin level was done. Post delivery these women were carefully watched for any complications. The patients and their neonates were followed till discharge. Amongst the 100 antenatal women who were randomly selected for the study, 50 had mild anaemia, 35 had moderate anaemia and 15 were with severe anaemia according to WHO grading of anaemia.

\subsection{Maternal haemoglobin}

Amongst the 100 antenatal women who participated, the range of haemoglobin levels was $3.8-10.7 \mathrm{grams} / \mathrm{dl}$. In participants with mild anaemia the range of haemoglobin was $10-10.7 \mathrm{gram} / \mathrm{dl}$ with a mean of $10.29 \pm 0.20 \mathrm{gram} / \mathrm{dl}$. For those with moderate anaemia mean haemoglobin levels were $9.06 \pm 0.57 \mathrm{gram} / \mathrm{dl}$ with a range of $8.0-9.8 \mathrm{gram} / \mathrm{dl}$ while for those with severe anaemia the haemoglobin ranged from 3.8- $6.9 \mathrm{gram} / \mathrm{dl}$ with a mean value of $5.99 \pm 0.91 \mathrm{gram} / \mathrm{dl}$ 


\section{Anemia distribution}

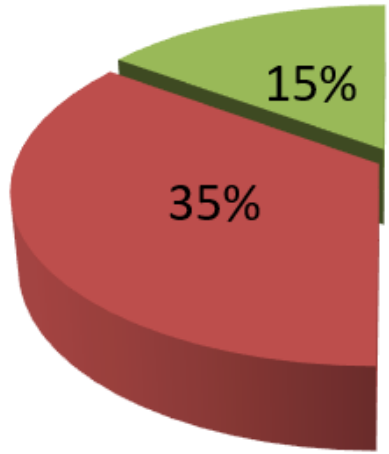

Mild Moderate

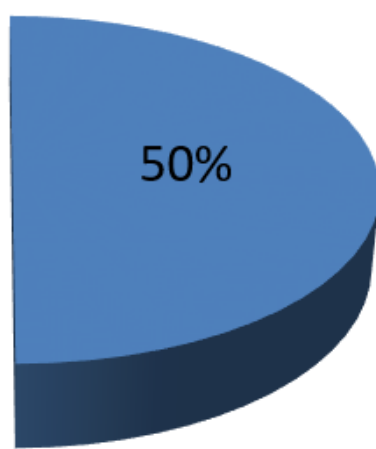

Severe
Fig. 2: Distribution of cases according to WHO grading of severity

Age of the pregnant females recruited in the study ranged from 20-34 years with a mean age of $22.9 \pm 0.99$ years. Mean age in mild anaemia group was $25.12 \pm 2.71 \mathrm{SD}$ in moderate anaemia group was $25.17 \pm 2.61 \mathrm{SD}$ and in severe anaemia group was $26.27 \pm 4.74 \mathrm{SD}$.

Because the parity significantly affects the iron status of the pregnant female it was taken into consideration after checking the demographic features of the study population. The mild anaemia group 32\% were nulliparous, 52\% were primiparous and $16 \%$ were multiparous while in the moderate anaemia group $25.71 \%$ were nulliparous, $65.71 \%$ were primiparous and $5.71 \%$ were multiparous. In the severe anaemia group $20 \%$ were nulliparous, $46.67 \%$ were primiparous and $33.33 \%$ were multiparous. This shows that parity is of significance for severity of Anaemia with the p-value 0.002 .

\subsection{Birth weight of neonates}

The birth weight of neonates born to these anaemic mothers were not significantly different. The mean birth weight of neonates was $2.56 \pm 0.31 \mathrm{~kg}$.

The mean birth weight of the participants with mild anaemia was $2.64 \pm 0.34 \mathrm{~kg}$ with moderate anaemia was $2.49 \pm 0.34 \mathrm{~kg}$ and with severe Anaemia was $2.42 \pm 0.25$ $\mathrm{kg}$.

\subsection{Maternal serum ferritin}

Serum ferritin has been considered as the gold standard in establishing the diagnosis of iron deficiency anaemia. The accepted cut-off level of serum ferritin, below which iron stores are considered to be depleted is less that $15 \mathrm{microgram} / \mathrm{L}$ and ferritin levels less than $12 \mathrm{microgram} / \mathrm{l}$ is associated with iron deficiency Anaemia.

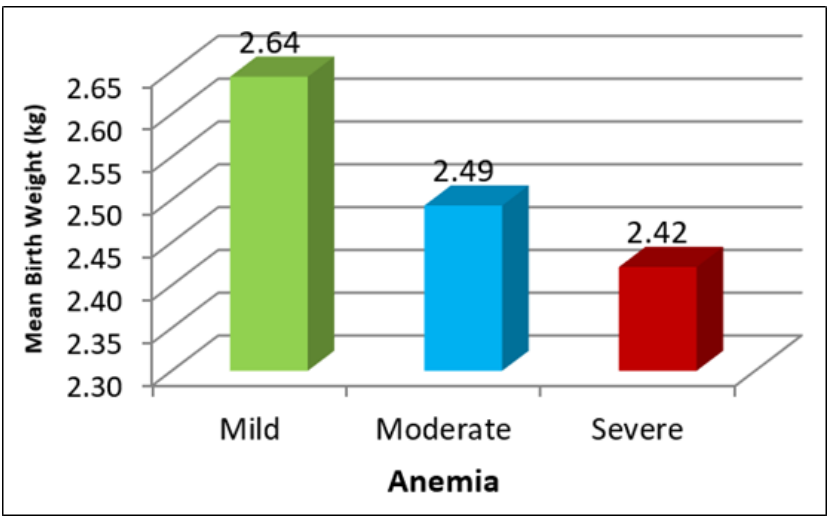

Fig. 3: Mean birth weight according to severity of anaemia

The cut-off for serum ferritin in this study was considered $<15$ microgram/L.

\subsection{Cord blood haemoglobin}

Cord blood haemoglobin from neonates of anaemic mothers was estimated. The mean of cord blood haemoglobin in our study was $14.75 \pm 1.08$ grams/dl with a range of 11.2- 16.7 grams/dl.

\subsection{Cord blood serum ferritin}

Cord blood Serum ferritin from neonates of anemic mothers was also estimated. The mean of cord blood Serum ferritin in our study was $57.36 \pm 19.48$ micro grams $/ \mathrm{L}$ with a range of 10.4-136.2 microgram/L.

In mothers with mild anaemia, the cord blood serum ferritin value ranged from 41.7- $136.2 \mathrm{microgram} / \mathrm{L}$ with a mean value of $69.47 \pm 12.8 \mathrm{SD}$. Those with moderate Anaemia, mean value was $55.36 \pm 8.73 \mathrm{SD}$ ranging from 30.3-76.1 grams/dl. While in those with severe anaemia, the cord blood Serum ferritin value ranged from 10.4-29.8 microgram/l with mean value of $21.66 \pm 5.18 \mathrm{SD}$.

After comparing the demographic characteristics in the participants with mild, moderate and severe anaemia association between various parameters were established.

Those with severe anaemia, a positive association was found between maternal Serum ferritin and cord blood haemoglobin with p-value 0.004 and maternal haemoglobin and cord blood serum ferritin with p-value of 0.009. A positive association was found between maternal haemoglobin and cord blood haemoglobin ( $p$ value- 0.007 )

The usual hospital protocols were followed and the antenatal women and there neonates were followed till discharge.

Blood transfusion was given according to severity of Anaemia, 93.33\% participants in the group with severe anaemia received blood transfusion was significant. (the chi square $\mathrm{p}$-value $<0.001$ ). 
Table 1: Distribution of cases according to gravidity

\begin{tabular}{lccccccc}
\hline Gravida & Total cases & $\mathbf{n}$ & Mild & \multicolumn{2}{c}{ Moderate } & \multicolumn{2}{c}{ Severe } \\
1 & 22 & 11 & $22 \%$ & $\mathbf{n}$ & $\mathbf{\%}$ & $\mathbf{n}$ & $20.00 \%$ \\
2 & 41 & 22 & $44 \%$ & 15 & $42.86 \%$ & 4 & $26.67 \%$ \\
3 & 25 & 12 & $24 \%$ & 9 & $25.71 \%$ & 4 & $26.67 \%$ \\
4 & 10 & 5 & $10 \%$ & 3 & $8.57 \%$ & 2 & $13.33 \%$ \\
5 & 2 & 0 & $0 \%$ & 0 & $0.00 \%$ & 2 & $13.33 \%$ \\
Total & 100 & 50 & $100 \%$ & 35 & $100 \%$ & 15 & $100 \%$ \\
\hline
\end{tabular}

Table 2: Correlation among severity of anaemia and maternal serum ferritin on basis of $\mathrm{p}$ value

\begin{tabular}{lccc}
\hline $\begin{array}{l}\text { Maternal haemoglobin } \\
\text { (gram/l) }\end{array}$ & Maternal Serum Ferritin (microgram/l) & P value & Correlation \\
Mild anemia (10-10.9) & $8-13.2$ & 0.926 & No \\
Moderate (7-7.9) & $5.8-9.2$ & 0.115 & No \\
Severe $(<7)$ & $1.2-6.9$ & 0.000 & Yes \\
\hline
\end{tabular}

Table 3: Distribution of cases according to cord blood haemoglobin

\begin{tabular}{lcccccc}
\hline Cord Blood Haemoglobin $(\mathbf{g r a m} / \mathbf{d l})$ & & & & & \\
$<11$ & $11-11.9$ & $12-12.9$ & $13-13.9$ & $14-14.9$ & $15-15.9$ & $16-16.9$ \\
0 & 1 & 5 & 16 & 28 & 38 & 12
\end{tabular}

Table 4: Distribution of cases according to cord blood serum ferritin

\begin{tabular}{lcccccc}
\hline \multicolumn{2}{l}{ Cord Blood Serum Ferritin (microgram/l) } & & & & \\
$<20$ & $20-39$ & $40-59$ & $60-79$ & $80-99$ & $100-119$ & $120-140$ \\
5 & 11 & 32 & 49 & 2 & 0 & 1 \\
\hline
\end{tabular}

Table 5: Relation between maternal and neonatal iron stores in mild Anaemia

\begin{tabular}{llccc} 
For Mild Anaemia & \multicolumn{1}{c}{$\begin{array}{c}\text { Maternal } \\
\text { haemoglobin }\end{array}$} & $\begin{array}{c}\text { Maternal Serum } \\
\text { Ferritin }\end{array}$ & $\begin{array}{c}\text { Cord blood } \\
\text { haemoglobin }\end{array}$ & Cord blood Ferritin \\
Maternal & Correlation & 0.013 & -0.169 & 0.086 \\
haemoglobin & p-value & 0.926 & 0.234 & 0.552 \\
Maternal Serum & Correlation & & 0.062 & -0.006 \\
Ferritin & p-value & & 0.668 & 0.966 \\
Cord blood & Correlation & & & 0.155 \\
haemoglobin & p-value & & & 0.277
\end{tabular}

Table 6: Relation between maternal and neonatal iron stores in moderate Anaemia

\begin{tabular}{|c|c|c|c|c|c|}
\hline \multicolumn{2}{|c|}{ For Moderate Anaemia } & \multirow{3}{*}{$\begin{array}{c}\text { Maternal } \\
\text { haemoglobin }\end{array}$} & \multirow{2}{*}{$\begin{array}{c}\text { Maternal Serum } \\
\text { Ferritin } \\
0.262\end{array}$} & \multirow{2}{*}{$\begin{array}{c}\text { Cord blood } \\
\text { haemoglobin } \\
0.625\end{array}$} & \multirow{2}{*}{$\begin{array}{c}\text { Cord blood serum } \\
\text { Ferritin } \\
0.697\end{array}$} \\
\hline Maternal & Correlation & & & & \\
\hline haemoglobin & p-value & & 0.115 & 0.000 & 0.000 \\
\hline Maternal serum & Correlation & & & 0.295 & 0.181 \\
\hline Ferritin & $\mathrm{p}$-value & & & 0.073 & 0.292 \\
\hline Cord blood & Correlation & & & & 0.468 \\
\hline haemoglobin & p-value & & & & 0.002 \\
\hline
\end{tabular}

Table 7: Relation between maternal and neonatal stores in severe Anaemia

\begin{tabular}{|c|c|c|c|c|c|}
\hline \multicolumn{2}{|c|}{ For Severe Anaemia } & $\begin{array}{c}\text { Maternal } \\
\text { Haemoglobin }\end{array}$ & \multirow{2}{*}{$\begin{array}{c}\text { Maternal Serum } \\
\text { Ferritin } \\
0.763\end{array}$} & \multirow{2}{*}{$\begin{array}{c}\text { Cord blood } \\
\text { Haemoglobin } \\
0.369\end{array}$} & \multirow{2}{*}{$\begin{array}{c}\text { Cord blood Ferritin } \\
0.633\end{array}$} \\
\hline Maternal & Correlation & & & & \\
\hline Haemoglobin & p-value & & 0.000 & 0.007 & 0.002 \\
\hline Maternal Serum & Correlation & & & 0.491 & 0.574 \\
\hline Ferritin & $\mathrm{p}$-value & & & 0.036 & 0.009 \\
\hline Cord blood & Correlation & & & & 0.502 \\
\hline Ferritin & p-value & & & & 0.031 \\
\hline
\end{tabular}




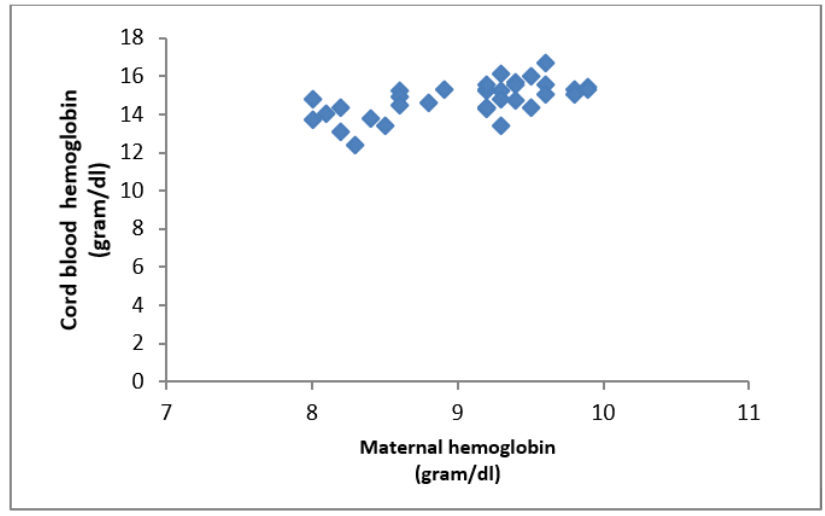

Fig. 4: Graph showing relation of Maternal and Cord Blood Haemoglobin according to grading of Anaemia

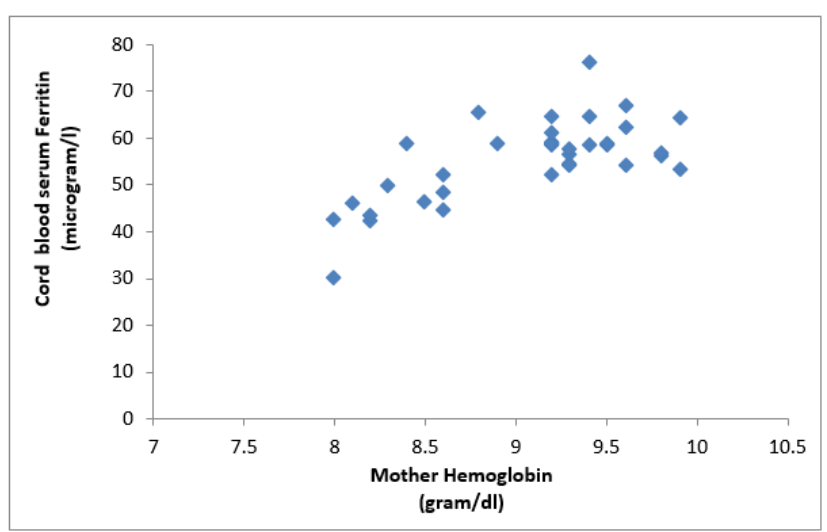

Fig. 5: Graph showing relation of Maternal Haemoglobin and Cord Blood Ferritin according to grading of Anaemia

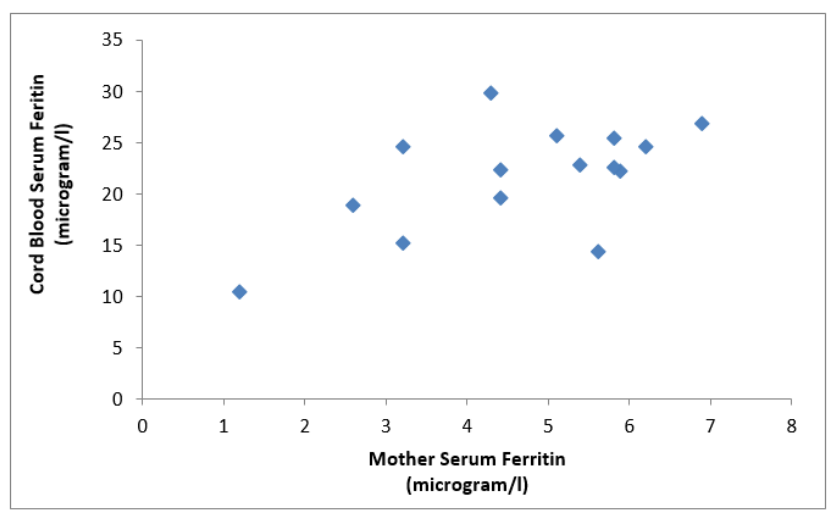

Fig. 6: Graph showing relationship of Maternal and Cord Blood Serum Ferritin according to grading of Anaemia

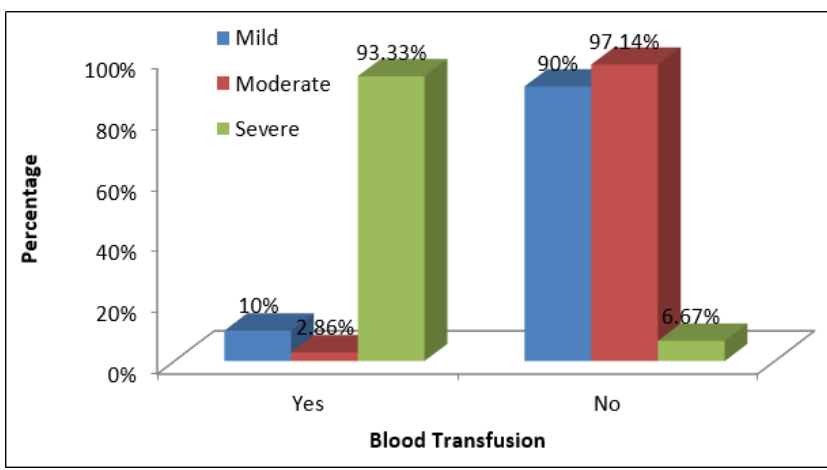

Fig. 7: Percentage of cases who received blood transfusion

Out of 100 participating women, 5 women had postpartum haemorrhage which was managed conservatively.

\subsection{APGAR score}

All the neonates were given routine neonatal care. Amongst the neonates born to mothers with mild anaemia $4 \%$ had apgar score $<7$ at 5 minutes, with moderate anaemia $20 \%$ had apgar score $<7$ at 5 minutes and those born to mothers with severe anaemia $40 \%$ had apgar score $<7$ at 5 minutes.

Most of the neonates with poor apgar score at 5 were admitted to the nursery for observation with admission rate of $4 \%$ in mild anaemia group, $17.14 \%$ in moderate anaemia group and $26.67 \%$ severe anaemia group which was significant ( $\mathrm{p}$ value - 0.03). All of the neonates were discharged after observation. None of them required ventilatory support or had any sequele of respiratory depression.

\section{Discussion}

Age of pregnant females recruited in the study ranged from 20-34 years. The mean age was $22.9 \pm 0.99$ years. The mean age of the women was comparable to mean age of participants in the study done by Hadipour et al ${ }^{15}$ which was $25.6 \pm 4.9$ years with a range of $17-40$ years. In another study by Betelihem et al., ${ }^{16}$ the mean age of mother was 23 years with a range of 21-27 years where was comparable to our study. Adewumi et al ${ }^{15}$ studied a population between age groups of 17-41 years with a mean age of $28.98 \pm 4.79$ years.

All the patients were in their third trimester, with period of gestation ranging from 37 weeks to 40.6 weeks. Mean gestational age was $38.35 \pm 0.8 \mathrm{SD}$. It was comparable to the study done by Paulo et al, Betelihem et al., ${ }^{16}$ Adewuni et al, ${ }^{17}$ Hadipour et al ${ }^{15}$ and Jie Shao et al. ${ }^{18}$ where all the participating women were in their their third trimester with period of gestation >- 37 weeks.

In mild anaemia group 32\% were nulliparous, 52\% were primiparous and $16 \%$ were multiparous while in the 
Table 8: Distribution of cases according to apgar score at 5 minutes

\begin{tabular}{|c|c|c|c|c|c|c|}
\hline \multirow{2}{*}{$\begin{array}{l}\text { APGAR AT } 5 \\
\text { minutes }\end{array}$} & \multicolumn{2}{|c|}{ Mild } & \multicolumn{2}{|c|}{ Moderate } & \multicolumn{2}{|c|}{ Severe } \\
\hline & $\mathbf{N}$ & $\%$ & $\mathbf{n}$ & $\%$ & $\mathbf{n}$ & $\%$ \\
\hline$>7$ & 48 & $96 \%$ & 28 & $80.00 \%$ & 9 & $60.00 \%$ \\
\hline$<7$ & 2 & $4 \%$ & 7 & $20.00 \%$ & 6 & $40.00 \%$ \\
\hline Total & 50 & $100 \%$ & 35 & $100 \%$ & 15 & $100 \%$ \\
\hline
\end{tabular}

moderate anaemia group $25.71 \%$ were nulliparous $65.71 \%$ were primiparous and $5.71 \%$ were multiparous. In the severe anaemia group $20 \%$ were nulliparous, $46.67 \%$ were primiparous and $33.33 \%$ were multiparous. This shows that parity is of significance for severity of anaemia with pvalue of 0.002 . Similar study done by Hadipour et al ${ }^{15}$ there were significant differences $(p<0.39)$ of parity in relation to haemoglobin, with the mean parity of $1.5 \pm 0.6 \mathrm{SD}$ is anemic mothers as compared to $1.2 \pm 0.5$ in non-anemic mothers.

The study followed WHO grading for classifying severity of Anaemia. 50\% of the participating women had mild anaemia, $35 \%$ had moderate anaemia while $15 \%$ had severe anaemia.

The maternal haemoglobin ranged from $3.8 \mathrm{gm} / \mathrm{dl}$ to 10.7 $\mathrm{gm} / \mathrm{dl}$ with a mean of $9.77 \pm 1.55 \mathrm{gram} / \mathrm{dl}$. This was similar to the study done by Jie Shao et al ${ }^{18}$ where mean maternal haemoglobin was $11.6 \pm 1.2 \mathrm{gram} / \mathrm{dl}$. The mean value of maternal haemoglobin was $9.5 \pm 1.01 \mathrm{gram} / \mathrm{dl}$ in the study done by Adewumi et al ${ }^{17}$ while it was $10.2 \pm 0.4 \mathrm{gram} / \mathrm{dl}$ in the study done by Hadipour et al, ${ }^{15}$ Betelihem et al ${ }^{16}$ calculated the median value of $12.2 \mathrm{gram} / \mathrm{dl}$ with a range of $11.3-12.9 \mathrm{gram} / \mathrm{dl}$ in their study. In all these studies the values were similar to the value in our study.

In our study the mean value of serum ferritin was 9.77 \pm 13.53 microgram $/ 1$ with a range of 1.2-13.2 microgram/1 which showed that iron stores were depleted in woman with iron deficiency Anaemia. In participants with mild anemic, the range was from 8-13.2 microgram/L with mean value $12.64 \pm 1.87 \mathrm{SD}$. Those with moderate anaemia the range was from 5.8 to 9.2 microgram/L with mean value $7.87 \pm 1.04 \mathrm{SD}$. In the participants with severe anaemia, serum ferritin ranged from $1.2-6.9 \mathrm{microgram} / \mathrm{l}$ with the mean value of $4.67 \pm 1.56 \mathrm{SD}$. No correlation was found between the maternal haemoglobin and maternal serum ferritin levels in women with mild and moderate Anaemia with a chi-square $\mathrm{p}$ value of 0.926 and 0.115 respectively. But in cases of severe Anaemia a positive correlation was found with a p-value of 0.000 . This was similar to the study done by Jie Shao et al ${ }^{18}$ where the mean value of serum ferritin was $18.6 \pm 20.3$ microgram/l. While the results were not comparable to the study done by Adewumi et al ${ }^{17}$ where the mean value was $64.45 \pm 138.16$ microgram $/ 1$ which was in normal range. The mean value was $40 \pm 20$ micrograms with a range of $5.5-98.3$ micrograms/l in the study done by Hadipour et al ${ }^{15}$ and the median value was 45.5 microgram $/ 1$ ranging from $26.8-80.34$ microgram/l in the study done by
Betelihem et al $^{16}$ which were also in the normal range for serum ferritin.

The mean of the cord blood haemoglobin in our study was $14.75 \pm 1.08 \mathrm{gm} / \mathrm{dl}$ with a range of $11.2-16.7$ $\mathrm{gm} / \mathrm{dl}$. In mothers with mild anaemia, the cord blood serum ferritin value ranged from 41.7-136.2 microgram/L with a mean value of $69.47 \pm 12.8$ SD. Those with moderate Anaemia, mean value was $55.36 \pm 8.73 \mathrm{SD}$ ranging from 30.3-76.1 grams/dl. While in those with severe anaemia, the cord blood Serum ferritin value ranged from 10.4$29.8 \mathrm{microgram} / \mathrm{l}$ with mean value of $21.66 \pm 5.18 \mathrm{SD}$. No association was found between maternal haemoglobin and cord blood haemoglobin in mild anaemia with $\mathrm{p}$ value of 0.234 . Whereas a positive association was found in moderate and severe anaemia with $\mathrm{p}$ value of 0.000 and 0.007 respectively. Cord blood serum ferritin in our study ranged from $10.4-136.2$ microgram/l with a mean of 67.36 \pm 19.00 microgram/l. In mothers with mild Anaemia, the cord blood serum ferritin value ranged from 41.7- 136.2 microgram/L with a mean value of $69.47 \pm 12.8 S D$. Those with moderate Anaemia, mean value was $55.36 \pm 8.73 \mathrm{SD}$ ranging from 30.3-76.1 grams/dl. While in those with severe anaemia, the cord blood Serum ferritin value ranged from 10.4-29.8 microgram/1 with mean value of $21.66 \pm 5.18 \mathrm{SD}$. No association was found between maternal haemoglobin and cord blood serum ferritin in mild anaemia ( $\mathrm{p}$ value 0.552 ) while positive association was found in moderate and severe anaemia with $\mathrm{p}$ value of 0.000 and 0.002 respectively. No association was found between maternal serum ferritin and cord blood serum ferritin in mild and moderate anaemia with $\mathrm{p}$ value of 0.966 and 0.292 respectively. Whereas a positive association was found in severe anaemia with a pvalue of 0.009 . Gasper et $\mathrm{al}^{19}$ did a study where they studied 157 pregnant women living in Merida, Spain, during their third trimester of pregnancy and their newborns at birth, analyzing the mother's and the umbilical cord blood for haemoglobin, hematocrit, mean corpuscular haemoglobin concentration (MCHC), serum iron and serum ferritin. They observed statistically correlations between haemoglobin and hematocrit values of the mother with erythrocyte count, haemoglobin and hematocrit values of her child and between serum iron of mother and child. The blood levels in the umbilical cord did not decrease until the ferritin value of the mother was $<12$ micrograms/l. Under these conditions the ferritin levels in the umbilical cord blood (80.4 micrograms/l) were significantly lower than in those newborn infants whose mother had adequate ferritin levels 
(123 micrograms/l). They deduced that maternal iron status seems to condition, fetal iron status, partially, especially when the mother had some deficiencies. The results of this study was concordant with our study for women with severe anaemia and other similar studies.

\section{Conclusion}

The study supports the fact that placental iron transport is largely driven by fetal needs. When maternal iron reserves are depleted, the placenta responds to fetal cues with an increased transfer of maternal iron, steadily draining the mother of iron. Ultimately, however, the entire maternal unit becomes iron deficient and upregulation of the placental receptors cannot result in enough iron transfer to restore fetal iron pools to normative levels. The fetus will then start showing decreased serum ferritin and ultimately decreased Haemoglobin or signs of Iron deficiency at birth. After three months of age, iron stores are usually mobilized to meet the erythropoietic demands of an expanding total haemoglobin mass because breast milk is not sufficient to meet the demands of growth. As a result, the level of plasma ferritin declines. Infants with small iron stores will deplete iron earlier than those with ample iron store. Therefore with low iron stores have poor physical and neurological growth.

Thus, this study establishes the effect of iron deficiency anaemia on neonatal iron status with increasing severity of anaemia and emphasizes on the need for iron supplementation during pregnancy.

\section{Source of Funding}

None.

\section{Conflict of Interest}

None.

\section{References}

1. World Health Organization. Iron deficiency Anaemia assessment, prevention and control: a guide for programme managers. Geneva: World Health Organization; 2001.

2. CDC criteria for Anaemia in children and childbearing-aged women MMWR Morbidity Mortality Weekly Rep. 1989;38:400-4.

3. Indian Council of Medical Research and UNICEF, Report of Meeting on Prevention and Control of Nutrition Anaemia and Evaluation of Anaemia Prophylaxis Programme. An ICMR Task Force Study; 1989.

4. WHO. Haemoglobin concentrations for the diagnosis of anaemia and assessment of severity. Vitamin and Mineral Nutrition Information System. Geneva: World Health Organisation; 2011.

5. Sifakis S, Pharmakides G. Anaemia in pregnancy. Ann N Y Acad Sci. 2000;900:125-36.

6. Yaqoob N, Abbasi SM. Nutritional iron deficiency in our population. J Coll Physicians Surg Pak. 2002;12:395-7.
7. Liao QK, Kong PA, Gao J, Li FY, Qian ZM. Expression of ferritin receptor in placental microvilli membrane in pregnant women with different iron status at mid-term gestation. Eur J Clin Nutr. 2001;55(8):651-6.

8. Punnonen K, Irjala K, Rajamaki A. Serum Tf Receptor and its Ratio to Serum Rerritin in The Diagnosis of Iron Deficiency. Blood. 1997;89(3):1052-7.

9. McCann JC, Ames BN. An overview of evidence for a causal relation between iron deficiency during development and deficits in cognitive or behavioral function. Am J Clin Nutr. 2007;85(4):931-45.

10. World Health Organization and Food and Agriculture Organization, Joint Expert Consultation Report, Requirements of Vitamin A, Iron, Folate, and Vitamin B12. Rome, Food and Agriculture Organization of the United Nations, (FAO) Food and Nutrition Series; 1988.

11. Desforges JF, Oski FA. Iron Deficiency in Infancy and Childhood. $N$ Engl J Med. 1993;329(3):190-3.

12. Scholl TO. Iron status during pregnancy: setting the stage for mother and infant. Am J Clin Nutr. 2005;81(5):108.

13. McCann JC, Ames BN. An overview of evidence for a causal relation between iron deficiency during development and deficits in cognitive or behavioral function. Am J Clin Nutr. 2007;85(4):931-45.

14. Roncagliolo M, Garrido M, Walter T, Peirano P, Lozoff B. Evidence of altered central nervous system development in infants with iron deficiency anemia at $6 \mathrm{mo}$ : delayed maturation of auditory brainstem responses. Am J Clin Nutr. 1998;68(3):683-90.

15. Hadipour R, Norimah AK, Poh B, Firoozehchian F, Raheleh H, Akaberi A. Haemoglobin and Serum Ferritin Levels in Newborn Babies Born to Anaemic Iranian Women: a Cross-Sectional Study in an Iranian Hospital. Pak J Nutr. 2010;9(6):562-6.

16. Terefe B, Birhanu A, Nigussie P, Tsegaye A. Effect of Maternal Iron Deficiency Anemia on the Iron Store of Newborns in Ethiopia. Anemia. 2015;2015:1-6.

17. Adediran A, Adeyemo TA, Akanmu AS, Akinbami A, Gbadegesin A, Ogbenna A, et al. Cord blood haemoglobin and ferritin concentrations in newborns of anaemic and non-anaemic mothers in Lagos, Nigeria. Niger Med J. 2013;54(1):22-6.

18. Shao J, Lou J, Rao R, Georgieff MK, Kaciroti N, Felt BT, et al. Maternal serum ferritin concentration is positively associated with newborn iron stores in women with low ferritin status in late pregnancy. J Nutr. 2012;142(11):2004-9.

19. Tamura T, Goldenberg RL, Hou J, Johnston KE, Cliver SP, Ramey SL, et al. Cord serum ferritin concentrations and mental and psychomotor development of children at five years of age. J Pediatr. 2002;140:16570 .

\section{Author biography}

Monica Senior Resident

Sunita Maheshwari Senior Professor and Unit Head

Archana Bamaniya Associate Professor

Cite this article: Monica , Maheshwari S, Bamaniya A. Association of maternal serum ferritin concentration with newborn iron stores in anemic women in late pregnancy. Indian J Obstet Gynecol Res 2020;7(3):406-414. 